\title{
Desempenho de bezerras de corte em pastagem de azevém recebendo farelo de arroz com ou sem monensina
}

[Beef heifers performance in ryegrass pasture supplemented with rice bran with or without monensin]

\author{
L.L. Biscaíno ${ }^{1}$, M.G. Rocha ${ }^{1}$, L. Pötter ${ }^{*}$, L.R. Eloy ${ }^{1}$, A.M. da Fonseca Neto ${ }^{2}$, M.B. Alves ${ }^{1}$, \\ L.A. Graminho ${ }^{1}$, M.J.O. Sichonany ${ }^{1}$ \\ ${ }^{1}$ Universidade Federal de Santa Maria - UFSM - Santa Maria, RS \\ ${ }^{2}$ Empresa Brasileira de Pesquisa Agropecuária - EMBRAPA Cerrados - Planaltina, DF
}

\begin{abstract}
RESUMO
Foi estudado o desempenho de bezerras de corte em pastagem de azevém (Lolium multiflorum Lam.), com animais exclusivamente em pastejo ou recebendo farelo de arroz integral (FAI) em nível de $0,8 \%$ do peso corporal, associado ou não à monensina. $\mathrm{O}$ método de pastejo foi contínuo com número variável de animais. $\mathrm{O}$ delineamento experimental foi o inteiramente ao acaso, com medidas repetidas no tempo, com três tratamentos e três repetições de área. $\mathrm{O}$ uso de FAI associado ou não à monensina não expressou alteração na área pélvica das bezerras, na taxa de lotação e no ganho de peso por área. As bezerras que receberam FAI, com ou sem monensina, apresentaram maior ganho diário de peso corporal, peso corporal, escore de condição corporal e relação peso corporal:altura. O fornecimento de suplementação energética para bezerras de corte é uma alternativa viável em sistemas de produção que visam à redução da idade ao primeiro acasalamento.
\end{abstract}

Palavras-chave: ionóforo, Lolium multiflorum Lam., suplementação energética

\section{ABSTRACT}

The experiment was carried out with the objective of evaluating beef cattle heifer performance when exclusively grazing Italian ryegrass (Lolium multiflorum Lam.) pasture or supplemented with whole rice bran (WRB), equivalent to $0.8 \%$ of body weight, associated or not with monensin. The grazing method was "putand-take" stocking, in a completely randomized experimental design, with replicated measures over time, with three treatments and three replications of area. The use of WRB, associated or not with monensin, did not affect heifers' pelvic area, stocking rate and area weight gain. Animals fed WRB, with or without monensin, showed greater average daily gain, body weight, body condition score, and body weight:height ratio. Energetic supplementation for beef heifers is one viable option in production systems seeking age reduction at the first mating.

Keywords: ionophore, Lolium multiflorum Lam., energy supplementation

\section{INTRODUÇÃO}

Na pecuária de corte, em sistemas de cria, deve ser priorizada a alimentação das futuras matrizes, especialmente as bezerras com menos de um ano de idade. Para redução da sua idade ao primeiro acasalamento, podem ser utilizadas pastagens anuais de inverno e, entre elas, o azevém (Lolium multiflorum Lam.) é a espécie com maior área cultivada no Rio Grande do Sul.

Para intensificar o sistema de recria, além do uso exclusivo de pastagens, podem também ser utilizados suplementos energéticos e aditivos

Recebido em 27 de outubro de 2016

Aceito em 5 de agosto de 2017

*Autor para correspondência (corresponding author)

E-mail: potter.luciana@gmail.com alimentares. Entre os objetivos do uso de suplementos está o de aumentar a taxa de ganho de peso diário, o que possibilita que as fêmeas de corte entrem em puberdade mais cedo. Assim, é esperado aumento na eficiência da produção de bezerros por meio da diminuição da idade ao primeiro parto, além da maximização do uso da área, do potencial genético do animal e da liberação de áreas às demais categorias do rebanho. A escolha do suplemento a utilizar envolve disponibilidade regional, custo de aquisição, transporte e qualidade do produto. No Rio Grande do Sul, a produção média anual de arroz em casca na safra 2011/2012 foi de 7,7 milhões de toneladas (IRGA, 2012). A inclusão de ionóforos na dieta de bovinos, como a 
monensina sódica, provoca mudança na população microbiana e altera as proporções finais de ácidos graxos voláteis. Em estudo de metanálise, foi observado efeito linear do ionóforo na melhoria da eficiência alimentar, redução na ingestão da matéria seca e aumento no ganho médio diário (Duffield et al., 2012). O desempenho dos animais em pastejo, no entanto, tem apresentado resultados variados em resposta ao uso de ionóforos fornecidos via suplemento (Restle et al., 1999; Pötter et al., 1986), e novos experimentos nessa área ainda são necessários.

O objetivo deste experimento foi avaliar o desenvolvimento corporal de bezerras de corte dos oito aos 12 meses de idade em pastagem de azevém, recebendo farelo de arroz integral associado ou não à adição de monensina.

\section{MATERIAL E MÉTODOS}

O experimento foi realizado no Departamento de Zootecnia da Universidade Federal de Santa Maria, RS. O clima da região é subtropical úmido, conforme classificação de Köppen.

A área experimental utilizada foi de 7,2 hectares, com nove subdivisões, as quais constituíram as unidades experimentais e uma área anexa de 1,4 hectares. A pastagem de azevém (Lolium multiflorum Lam.) foi estabelecida em maio de 2011. O solo foi adubado com $250 \mathrm{~kg} \mathrm{ha}^{-1} \mathrm{da}$ fórmula 05-20-20 (NPK) e 63,5kg ha $\mathrm{he}^{-1}$ nitrogênio na forma de ureia, fracionados em três aplicações. A pastagem foi utilizada por 112 dias, com início de pastejo em 05 de julho e término em 26 de outubro.

Os tratamentos foram: bezerras mantidas exclusivamente sob pastejo em azevém; bezerras em pastagem de azevém recebendo $0,8 \%$ do peso corporal (PC) de farelo de arroz integral (FAI); bezerras em pastagem de azevém recebendo $0,8 \%$ do PC de FAI com adição de ionóforo (monensina). O método de pastejo foi contínuo, com número variável de animais reguladores para manter a massa de forragem em $1600 \mathrm{~kg} \mathrm{ha}^{-1}$ MS. Foram utilizadas três bezerras testes por unidade experimental, da raça Angus, com idade e peso inicial de oito meses e 139,0 $0 \pm 3,6 \mathrm{~kg}$, respectivamente. O FAI apresentou teores de $13,8 \%$ de proteína bruta (PB), 92,0\% de matéria seca (MS), 89,9\% de matéria orgânica, 25,8\% de fibra em detergente neutro (FDN), 12,45\% de extrato etéreo e $84,62 \%$ de digestibilidade in situ da matéria seca (DISMS) e foi fornecido diariamente às 14 horas. Foi adicionado calcário calcítico ao farelo de arroz, na proporção de $4 \%$. $\mathrm{O}$ ionóforo (monensina) foi fornecido na quantidade diária de $200 \mathrm{mg}$ por animal, adicionado ao FAI. O período de adaptação dos animais ao suplemento e ao ionóforo foi de sete dias.

A massa de forragem (MF) foi avaliada a cada 14 dias, por meio da técnica de estimativa visual com dupla amostragem. Na mesma ocasião, foi medida a altura do dossel, nos mesmos 20 pontos utilizados para estimativa da MF. A forragem proveniente dos cortes foi homogeneizada $\mathrm{e}$ dividida em duas subamostras, para determinação do teor de MS do pasto e para separação manual dos componentes estruturais. Após a separação e a secagem dos componentes estruturais do pasto, foi determinada a participação percentual de lâminas foliares, colmos, inflorescências, material morto e espécies indesejáveis e calculou-se a participação de cada componente na MF. A relação folha/colmo foi estimada por meio da divisão do valor da massa de lâmina foliar pelo valor da massa de colmos e foi expressa em kg de matéria seca de folhas $\mathrm{kg}^{-1}$ de MS de colmos.

A taxa de acúmulo diário de forragem (kg de MS $\mathrm{ha}^{-1} \operatorname{dia}^{-1}$ ) foi determinada pela utilização de três gaiolas de exclusão ao pastejo por unidade experimental, a cada 28 dias. A taxa de lotação ( $\mathrm{kg} \mathrm{ha}{ }^{-1}$ de PC) foi obtida pela equação: [peso corporal médio das bezerras-teste + (peso corporal dos animais reguladores $\mathrm{x}$ dias de permanência no piquete)/dias do período]. A oferta de forragem ( $\mathrm{kg}$ de MS $100 \mathrm{~kg}^{-1}$ de PC), expressa em \% do PC, foi determinada pelo somatório do valor médio da taxa de acúmulo de forragem em cada período experimental com o quociente da MF média pelo número de dias do período. A relação desse valor com a taxa de lotação média do período constituiu a oferta de forragem (OF). A oferta de lâminas foliares verdes foi obtida por meio da multiplicação da OF pelo percentual de lâminas na MF. Os teores de PB, DISMS e FDN foram determinados em amostras de forragem coletadas por simulação de pastejo. As amostras foram levadas à estufa com circulação forçada de ar a $55^{\circ} \mathrm{C}$, por 72 horas, e depois foram trituradas em moinho tipo Willey para posterior análise (AOAC, 1990). 
O ganho médio diário (GMD) foi obtido pela diferença entre peso final e inicial em cada período experimental e dividido pelo número de dias do período. As pesagens dos animais foram realizadas a cada 28 dias, respeitando jejum prévio de sólidos e líquidos de 12 horas. Por ocasião das pesagens, as bezerras foram submetidas a uma avaliação subjetiva do escore de condição corporal por avaliadores treinados, em escala que varia de 1,0 (muito magro) a 5,0 (muito gordo). Também nessas ocasiões, as medidas de altura de garupa foram efetuadas com auxílio de uma bengala de Thompson. O ganho de peso corporal por hectare $\left(\mathrm{kg} \mathrm{ha}^{-1}\right)$ foi obtida pelo somatório do ganho de peso dos animais testes mais o produto do GMD dos animais reguladores pelo número de dias em que cada animal regulador permaneceu no piquete.

Para avaliação do desenvolvimento corporal das bezerras, foram consideradas: altura de garupa, relação peso corporal:altura e área pélvica. A área pélvica foi determinada por meio da medida, por via transretal, com pelvímetro, dos seguintes pontos: distância entre os íleos (na porção mediana dos ossos) e distância entre o púbis e o sacro. Multiplicando-se essas medidas, obteve-se a área pélvica, em $\mathrm{cm}^{2}$.

O delineamento experimental foi o inteiramente ao acaso, com medidas repetidas no tempo, com três tratamentos e três repetições de área. Utilizou-se um modelo misto com o efeito fixo de sistemas alimentares, períodos de avaliação do experimento e suas interações e os efeitos aleatórios do resíduo e de potreiros aninhados nos sistemas alimentares, mediante o uso do procedimento MIXED do SAS, versão 9.2 (SAS, 2009). Foi realizado um teste de seleção das estruturas de covariância, utilizando-se o critério de informação bayesiano (BIC), para determinar o modelo que melhor representasse os dados. Quando observadas diferenças entre os sistemas alimentares e os períodos, as médias foram comparadas pelo emprego do recurso lsmeans. A interação entre sistemas alimentares e períodos foi desdobrada quando significativa a $5 \%$ de probabilidade, e as respostas das variáveis em função dos dias de utilização da pastagem foram modeladas por meio da função polinomial até terceira ordem. Os coeficientes de regressão foram comparados por meio de contrastes ortogonais.

\section{RESULTADOS E DISCUSSÃO}

Para as variáveis respostas do pasto, não houve interação entre sistemas alimentares $\times$ períodos de avaliação (Tab. 1). As bezerras, nos diferentes sistemas alimentares, pastejaram potreiros com semelhante $(\mathrm{P}>0,05)$ massa de forragem $\left(1490,0 \pm 134,9 \mathrm{~kg} \mathrm{ha}^{-1} \mathrm{MS}\right)$, altura do dossel $(10 \pm 0,68 \mathrm{~cm})$, oferta de forragem $(9,7 \pm 0,96 \%)$, relação folha:colmo $(3,1 \pm 0,28)$ e taxa de acúmulo de forragem $\left(38,9 \pm 2,75 \mathrm{~kg} \mathrm{ha}^{-1} \mathrm{dia}^{-1} \mathrm{de}\right.$ MS). Essas variáveis diferiram $(\mathrm{P}<0,05)$ nos períodos de utilização da pastagem de azevém, com exceção da taxa de acúmulo, que não diferiu entre os períodos $(\mathrm{P}>0,05)$.

Tabela 1. Valores médios dos atributos do pasto e taxa de lotação em bezerras de corte submetidas a diferentes sistemas alimentares

\begin{tabular}{|c|c|c|c|c|c|}
\hline \multirow{2}{*}{ Variáveis } & \multicolumn{3}{|c|}{ Sistemas alimentares } & \multirow{2}{*}{$\mathrm{P}^{8}$} & \multirow{2}{*}{ Média } \\
\hline & Azevém $^{5}$ & $\mathrm{FAI}^{6}$ & Monensina $^{7}$ & & \\
\hline Massa de forragem $^{1}$ & $1369,1 \pm 134,98$ & $1607,8 \pm 134,98$ & $1493,2 \pm 134,98$ & 0,997 & 1490.0 \\
\hline Altura do dossel ${ }^{2}$ & $10,5 \pm 0,72$ & $9,9 \pm 0,72$ & $9,8 \pm 0,72$ & 0,357 & 10,0 \\
\hline Oferta de forragem ${ }^{3}$ & $9,4 \pm 0,93$ & $9,6 \pm 0,99$ & $10,0 \pm 0,99$ & 0,374 & 9,7 \\
\hline Relação folha:colmo & $2,9 \pm 0,29$ & $3,0 \pm 0,29$ & $3,4 \pm 0,27$ & 0,820 & 3,1 \\
\hline Proteína bruta $^{3}$ & $23,7 \pm 0,68$ & $23,5 \pm 0,68$ & $24,3 \pm 0,68$ & 0,114 & 23,8 \\
\hline Fibra em detergente neutro ${ }^{3}$ & $48,5 \pm 0,53$ & $48,2 \pm 0,53$ & $47,8 \pm 0,53$ & 0,362 & 48,1 \\
\hline Digestibilidade in situ $\mathrm{MS}^{3}$ & $83,6 \pm 1,42$ & $80,9 \pm 1,42$ & $80,6 \pm 1,42$ & 0,495 & 81,7 \\
\hline Taxa de lotação $^{4}$ & $981,8 \pm 50,12$ & $1073,1 \pm 50,12$ & $1023,8 \pm 50,12$ & 0,694 & 1026,2 \\
\hline
\end{tabular}

${ }^{1} \mathrm{~kg} \mathrm{ha}^{-1} \mathrm{MS} ;{ }^{2} \mathrm{~cm} ;{ }^{3} \mathrm{~kg}$ MS $100^{-1} \mathrm{~kg}$ PC; ${ }^{4} \mathrm{~kg} \mathrm{ha}^{-1}$ do PC; ${ }^{5}$ azevém: bezerras exclusivamente em pastagem de azevém;

${ }^{6} \mathrm{FAI}$ : bezerras em pastagem de azevém recebendo $0,8 \%$ do peso corporal de farelo de arroz integral; ${ }^{7}$ monensina: bezerras em pastagem de azevém recebendo $0,8 \%$ do peso corporal $+200 \mathrm{mg}$ de monensina; $\mathrm{P}^{8}$ : probabilidade. 
Os valores de massa de forragem (Pilau et al., 2005), altura do dossel (Pontes et al., 2004) e oferta de forragem (Gibb e Treacher, 1976) indicam que não ocorreu limitação do consumo de forragem. A cada dia de utilização da pastagem, a relação folha:colmo foi reduzida em $0,06 \quad\left(\hat{Y}=7,7-0,06 x ; \quad P<0,0001 ; \quad R^{2}=0,82\right) \quad$ em consequência da redução do aparecimento de novas folhas e da prioridade do uso das reservas da planta para formação dos órgãos reprodutivos. $\mathrm{O}$ valor médio da taxa de acúmulo de forragem foi de $38,9 \mathrm{~kg} \mathrm{ha}^{-1} \mathrm{dia}^{-1}$ de MS e está dentro dos valores observados em pastagens de azevém (Difante et al., 2005).

As variáveis teor de proteína bruta (PB), teor de fibra em detergente neutro (FDN) e digestibilidade in situ da matéria seca (DISMS) no pasto colhido por simulação de pastejo não apresentaram interação sistemas alimentares $\mathrm{x}$ períodos de avaliação (Tab. 1). As bezerras, nos diferentes sistemas alimentares, colheram forragem com valor semelhante $(\mathrm{P}>0,05)$ de $\mathrm{PB}$ $(23,8 \%)$, FDN $(48,1 \%)$ e DISMS $(81,7 \%)$. O percentual de $\mathrm{PB}$ se ajustou ao modelo de regressão linear decrescente $\hat{(\hat{Y}}=30,19-0,09 x$; $\left.\mathrm{P}<0,0001 ; \mathrm{R}^{2}=0,68\right)$. No último dia de utilização da pastagem, o teor de PB do pasto aparentemente consumido pelos animais foi de $20,1 \%$ e, mesmo nessa ocasião, os animais tiveram oportunidade de colher forragem com teor de $\mathrm{PB} 59 \%$ superior às suas exigências para ganhos de 0,965kg (NRC, 1996). O teor de FDN no pasto proveniente da simulação de pastejo foi inferior ao valor de 55-60\%, considerado como limitante ao consumo (Van Soest, 1994). A DISMS se ajustou ao modelo de regressão linear decrescente $\left(\hat{\mathrm{Y}}=96,4-0,21 \mathrm{x} ; \mathrm{P}<0,0001 ; \mathrm{R}^{2}=0,68\right)$, em decorrência do aumento dos tecidos de sustentação da planta, constituídos por carboidratos estruturais e lignina, com o avanço do seu ciclo fenológico.

Houve interação $(\mathrm{P}<0,037)$ entre sistemas alimentares $\times$ períodos de avaliação para o peso corporal (PC) das bezerras que receberam suplemento e exclusivamente em azevém. A equação de regressão do $\mathrm{PC}$ em função dos dias de pastejo foi similar $(\mathrm{P}>0,05)$ para bezerras que receberam farelo de arroz integral (FAI) e FAI mais monensina $\left(\hat{\mathrm{Y}}=135,95+1,13 \mathrm{x} ; \mathrm{R}^{2}=0,98\right.$; $\mathrm{P}<0,0001)$. A evolução do peso corporal de bezerras exclusivamente em azevém também se ajustou ao modelo de regressão linear crescente
$\left(\hat{\mathrm{Y}}=130,89+0,98 \mathrm{x} ; \quad \mathrm{R}^{2}=0,97 ; \quad \mathrm{P}<0,0001\right) . \quad$ De acordo com os modelos de regressão, o ganho de peso adicional das bezerras que receberam suplemento foi $15,3 \%$ superior ao ganho em relação aos animais exclusivamente em pastejo. As forrageiras, mesmo quando classificadas como de boa qualidade, são caracterizadas pelo baixo conteúdo de carboidratos solúveis, associado à elevada concentração de proteína degradável no rúmen (Horn et al., 2005). O maior ganho de peso dos animais que recebem suplementos energéticos nesse tipo de pastagem é explicado pela sincronização que ocorre entre a energia adicional proveniente do suplemento e o $\mathrm{N}$ oriundo da degradação da proteína da forragem. Assim, o desempenho é aumentado pelo melhor uso ruminal da proteína degradável e pelo aumento da síntese de proteína microbiana, além de redução das perdas de $\mathrm{N}$ na urina (Van Vuuren et al., 1993).

Várias hipóteses podem explicar a inexistência de diferenças no desenvolvimento de bezerras de corte que receberam monensina, quando comparadas aos animais que receberam FAI exclusivo. Uma delas é que o fornecimento de monensina não aumenta a digestibilidade do pasto, uma vez que o azevém já apresenta elevada digestibilidade (Tab. 1). Mesmo com o decréscimo da digestibilidade do azevém em $0,21 \%$ por dia, a digestibilidade do pasto esteve sempre acima de 70\%. A digestibilidade está relacionada com o aumento na taxa da degradação ruminal, o que aumenta a taxa de passagem do rúmen e, geralmente, está associado a um aumento da concentração de propionato (Maas et al., 2001). Também Restle et al. (1999) não observaram diferença no desempenho de novilhos em pastejo em forrageiras de estação fria quando a lasalocida foi adicionada ao suplemento. Por outro lado, Potter et al. (1986) observaram aumento de $0,09 \mathrm{~kg}$ dia $^{-1}$ de bovinos em pastejo recebendo suplemento associado à monensina.

Outra hipótese a considerar sobre a ausência de resposta ao uso da monensina é que a maior proporção de carboidratos não estruturais fornecidos pelo suplemento energético (FAI) aumenta, por si só, a eficiência do uso do $\mathrm{N}$ do pasto e melhora o desempenho dos animais. Além disso, a ação da monensina pode ter sido menos necessária no que diz respeito ao seu efeito positivo sobre o $\mathrm{pH}$ ruminal quando os 
bovinos estão em pastejo. Nessa condição, o pH ruminal se mantém mais próximo dos valores considerados adequados para que ocorra digestão da fibra. Em bovinos confinados, a ação da monensina sobre o $\mathrm{pH}$ é mais relevante (Maas et al., 2001).

As bezerras que receberam FAI com ou sem ionóforo, em 112 dias de pastejo, ganharam $28 \%$ de peso corporal em relação ao peso adulto projetado (Tab. 2). Para viabilizar o seu acasalamento aos 12-13 meses idade, elas precisariam ter $37 \%$ do peso corporal adulto por ocasião do início do pastejo, em 05 de julho. Nessa ocasião, o peso corporal das bezerras correspondeu a $30,9 \%$ do seu peso adulto, o que, por si só, inviabilizaria seu acasalamento no 'sistema um ano'. As bezerras exclusivamente em azevém ganharam $24 \%$ de peso corporal em relação ao peso adulto e, quando exclusivamente em pastejo, deveriam possuir, então, $41 \%$ do seu peso adulto, ou seja, $184,5 \mathrm{~kg}$. O peso das novilhas aos 12-13 meses de idade é altamente dependente da combinação da variação no peso à desmama e do ganho de peso durante a recria proporcionado pelo potencial genético de cada animal (Pilau e Lobato, 2006).

O peso alvo para manifestação da puberdade nas novilhas de corte corresponde a $65 \%$ do peso adulto das vacas do rebanho e deve ser atingido antes do início do período de acasalamento (NRC, 1996). Considerando o peso adulto de $450 \mathrm{~kg}$ para essas fêmeas, mantendo o mesmo ganho diário de peso, o peso alvo de $293 \mathrm{~kg}$ seria atingido em 27 e 53 dias para as bezerras que receberam suplemento e exclusivamente em azevém, respectivamente. McCartor et al. (1979) observaram que novilhas de corte foram 29,5 dias mais jovens no aparecimento da puberdade quando receberam monensina, fato não verificado no presente experimento em que o efeito do FAI exclusivo não foi diferente do FAI mais a inclusão de monensina. Esses autores atribuíram o decréscimo na idade à puberdade ao efeito da monensina na fermentação ruminal, com aumento na produção de propionato.

Tabela 2. Valores médios dos parâmetros de desempenho e medidas corporais de bezerras em diferentes sistemas alimentares

\begin{tabular}{cccccc}
\hline Variáveis & \multicolumn{3}{c}{ Sistemas alimentares } & $\mathrm{P}^{9}$ & \multirow{2}{*}{ Média } \\
\cline { 2 - 4 } & Azevém $^{6}$ & $\mathrm{FAI}^{7}$ & Monensina $^{8}$ & & \\
\hline Ganho médio diário $^{1}$ & $965,3 \pm 0,04$ & $1052.1 \pm 0.04$ & $1145.8 \pm 0.04$ & 0.029 & 1054.4 \\
Ganho de peso corporal por área $^{2}$ & $566,9 \pm 84,7$ & $651,7 \pm 84,7$ & $694,2 \pm 84,7$ & 0,283 & 637,6 \\
Altura de garupa $^{3}$ & $112,6 \pm 0,79$ & $112,1 \pm 0,79$ & $113,0 \pm 0,79$ & 0,751 & 112,6 \\
Relação peso corporal:altura $^{4}$ & $2,15 \pm 0,04$ & $2,30 \pm 0,04$ & $2,40 \pm 0,04$ & 0,011 & 2,28 \\
Área pélvica $^{5}$ & $153,1 \pm 5,21$ & $156,3 \pm 5,21$ & $165,2 \pm 5,21$ & 0,305 & 158,2 \\
\hline
\end{tabular}

${ }^{1} \mathrm{~g} \mathrm{dia}{ }^{-1} ;{ }^{2} \mathrm{~kg} \mathrm{ha}^{-1} ;{ }^{3} \mathrm{~cm} ;{ }^{4} \mathrm{~kg} \mathrm{~cm}^{-1} ;{ }^{5} \mathrm{~cm}^{2} ;{ }^{6}$ azevém: bezerras exclusivamente em pastagem de azevém; ${ }^{7} \mathrm{FAI}$ : bezerras em pastagem de azevém recebendo $0,8 \%$ do peso corporal de farelo de arroz integral; ${ }^{8}$ monensina bezerras em pastagem de azevém recebendo $0,8 \%$ do peso corporal $+200 \mathrm{mg}$ de monensina; $\mathrm{P}^{9}$ : probabilidade.

Não houve interação $(\mathrm{P}>0,05)$ entre sistemas alimentares $\times$ períodos para taxa de lotação (TL). Não houve diferença $(\mathrm{P}>0,05)$ entre sistemas alimentares para essa variável (Tab. 1). A TL diferiu entre os períodos avaliados $(\mathrm{P}<0,0001)$. Quando são ofertados suplementos energéticos para bovinos em pastejo em forrageiras hibernais é esperado que o consumo do pasto seja reduzido, ocasionando aumento na taxa de lotação. Esse efeito, no entanto, não foi observado, o que pode ter sido ocasionado pelo nível do suplemento oferecido, $0,8 \%$ do $\mathrm{PC}$, pois Pötter et al. (2010) observaram que o efeito de substituição do consumo de pasto pelo consumo de suplemento aumenta à medida que aumenta a quantidade de suplemento em proporção ao peso corporal. Ao considerarem bezerras com peso corporal médio de $140 \mathrm{~kg}$, os diferentes sistemas alimentares permitiram manter 7,3 bezerras por hectare.

O ganho de peso por área foi similar quando foi fornecido ou não suplemento aos animais, com média de $637,6 \pm 84,7 \mathrm{~kg} \mathrm{ha}^{-1}$ de PC. O ganho de peso por área por dia foi de $5,7 \mathrm{~kg}$, sendo um importante indicador biológico no manejo a ser empregado e diretamente relacionado com a rentabilidade da exploração da pastagem. O ganho de peso por área é um indicativo da eficiência de utilização das pastagens e/ou do número de novilhas atingindo o peso alvo por ocasião do primeiro acasalamento (Pötter et al., 2010). 
Não houve interação $(\mathrm{P}>0,098)$ para sistema alimentar e períodos de avaliação para o escore de condição corporal (ECC). Escore de condição corporal superior a três é preconizado por Rocha e Lobato (2002) para que as novilhas possam ser acasaladas. Esse escore foi atingido aos 28 dias de pastejo $\left(\hat{\mathrm{Y}}=2,72+0,0099 \mathrm{x} ; \quad \mathrm{R}^{2}=0,92\right.$; $\mathrm{P}<0,0001)$ em bezerras que receberam FAI com ou sem ionóforo e aos 45 dias $(\hat{\mathrm{Y}}=2,58+0,0091 \mathrm{x}$; $\left.\mathrm{R}^{2}=0,93 ; \mathrm{P}<0,0001\right)$ em bezerras exclusivamente em pastejo. Bezerras de corte que atingem escore de condição corporal mais cedo na estação podem manifestar a puberdade precocemente, o que propicia a ocorrência de vários ciclos estrais antes do início da estação de acasalamento e aumenta potencialmente a taxa de prenhez (Barcellos et al., 2003).

Bezerras de corte que receberam suplemento e as que permaneceram exclusivamente no azevém tiveram ECC ao final da utilização da pastagem de 3,84 e 3,66 , respectivamente. O maior ECC em bezerras que receberam suplemento, no final do período de pastejo, é determinado pela composição do ganho de peso, com maior deposição de gordura, sendo esse um importante mecanismo de surgimento da puberdade e posterior fertilidade (Patterson et al., 1992). Assim, ruminantes recebendo suplemento energético em pastagem com elevado teor de PB tendem a acumular gordura mais precocemente em relação ao uso exclusivo de azevém.

Não houve diferença $(\mathrm{P}>0,05)$ para a área pélvica de bezerras nos diferentes sistemas alimentares (Tab. 2). As bezerras apresentaram área pélvica média de $158,2 \mathrm{~cm}^{2}$, valor dentro do recomendado de 140 a $170 \mathrm{~cm}^{2}$, para bezerras que serão acasaladas com um ano de idade, uma vez que essa variável mostra elevada correlação com a facilidade ao parto de novilhas de corte (Brinks, 1990).

A relação peso corporal:altura $(\mathrm{P}: \mathrm{H})$ aos 12 meses de idade diferiu entre as novilhas nos sistemas alimentares $(\mathrm{P}<0,05)$. Tal relação foi de $2,35 \mathrm{~kg} \mathrm{~cm}^{-1}$ para as bezerras que receberam FAI como suplemento associado ou não à monensina, sendo 9,3\% superior aos animais exclusivamente no azevém $(\mathrm{P}<0,05)$. Essa maior relação $\mathrm{P}: \mathrm{H}$ das bezerras que receberam suplemento ocorreu devido à superioridade de $22 \mathrm{~kg}$ no seu peso corporal, pois a altura média das bezerras em todos sistemas alimentares foi de $112 \mathrm{~cm}$
$(\mathrm{P}>0,05)$. Fêmeas bovinas atingem, geralmente, a altura adulta antes do peso adulto, sendo este o principal determinante da adequada relação $\mathrm{P}: \mathrm{H}$. Essas bezerras, no entanto, mesmo recebendo suplemento, não alcançaram o valor de $2,53 \mathrm{~kg}$ $\mathrm{cm}^{-1}$, considerado o valor de referência para que as fêmeas manifestem puberdade (Fox et al., 1988). Em sistemas de produção que preconizam redução da idade ao primeiro acasalamento, o fornecimento de suplementos energéticos se torna uma alternativa viável, proporcionando melhoria no desempenho dos animais.

\section{CONCLUSÃO}

O fornecimento de farelo de arroz associado ou não à monensina para bezerras de corte em pastagem de azevém promove maior ganho diário de peso corporal, peso corporal, escore de condição corporal e relação peso corporal:altura. O ganho de peso por área e a taxa de lotação não são influenciados pelo uso de farelo de arroz como suplemento.

\section{COMITÊ DE ÉTICA E BIOSSEGURANÇA}

A pesquisa foi aprovada pelo Comitê de Ética em Pesquisa na instituição de origem, protocolada sob $n^{\circ}$. 014/2012.

\section{REFERÊNCIAS}

BARCELlOS, J.O.J.; COSTA, E.C.; SILVA, M.D. Crescimento de fêmeas bovinas de corte aplicado aos sistemas de cria. Sistemas de produção em bovinos de corte. Porto Alegre: Universidade Federal do Rio Grande do Sul, 2003. 72p. (Publicação ocasional, 1).

BRINKS, J.S. Genetic influences on reproductive performance of two-year-old beef females. Colorado: Colorado State University, 1990. p.1-11.

DIFANTE, G.S.; MARCHEZAN, E.; ROCHA, M.G. et al. Produção de forragem e rentabilidade da recria de novilhos de corte em área de várzea. Rev. Bras. Zootec., v.34, p.433-441, 2005.

DUFFIELD, T.F.; MERRILL, J.K.; BAGG, R.N. Meta-analysis of the effects of monensin in beef cattle on feed efficiency, body weight gain, and dry matter intake. J. Anim. Sci., v.90, p.45834592, 2012. 
FOX, D.G.; SNIFFEN, C.J.; O'CONNOR, J.D. Adjusting nutrient requirements of beef cattle for animal and environmental variations. J. Anim. Sci., v.66, p.1475-1495, 1988.

GIBB, M.J.; TREACHER; T.T. The effect of herbage allowance on herbage intake and performance of lambs grazing perennial ryegrass and red clover swards. J. Agric. Sci., v.86, p.355$365,1976$.

HORN, G.W.; BACK, P.A.; ANDRAE, J.G. et al. Designing supplements for stocker cattle grazing wheat pasture. J. Anim. Sci., v.83, p.6978, 2005.

INSTITUTO RIO GRANDENSE DO ARROZIRGA. Lavoura arrozeira. Porto Alegre. v.60, $\mathrm{n}^{\mathrm{o}} .458,2012$

MAAS, J.A.; WILSON, G.F.; MCCUTCHEON, S.N. et al. The effect of season and monensin sodium on the digestive characteristics of autumn and spring pasture fed to sheep. J. Anim. Sci., v.79, p.1052-1058, 2001.

MCCARTOR, M.M.; RANDEL, R.D.; CARROLL, L.H. Dietary alteration of ruminal fermentation on efficiency of growth and onset of puberty in Brangus heifers. J. Anim. Sci., v.48, p.488-494, 1979.

NUTRIENT requirements of beef cattle. Washington: National Academy Press, 1996. 242p.

OFFICIAL methods of analysis. Virginia: AOAC, 1990. 1298p.

PATTERSON, D.J.; PERRY, R.C.; KIRACOFE, G.H. et al. Management considerations in heifer development and puberty. J. Anim. Sci., v,70, p.4018-4035, 1992.

PILAU, A.; LOBATO, J.F.P. Recria de bezerras com suplementação no outono e pastagem cultivada no inverno. Rev. Bras. Zootec., v.35, p.2388-2396, 2006.
PILAU, A.; ROCHA, M.G.; RESTLE, J. et al. Desenvolvimento de novilhas de corte recebendo ou não suplementação energética em pastagem com diferentes disponibilidades de forragem. Rev. Bras. Zootec., v.34, p.1483-1492, 2005.

PONTES, L.S.; CARVALHO, P.C.F.; NABINGER, C. et al. Fluxo de biomassa em pastagem de azevém anual (Lolium multiflorum Lam) manejada em diferentes alturas. Rev. Bras. Zootec., v.33, p.529-537, 2004.

POTTER, E.L.; MULLER, R.D.; WRAY, M.I. et al. Effect of monensin on the performance of cattle on pasture or fed harvested forages in confinement. J. Anim. Sci., v.62, p.583-592, 1986.

PÖTTER, L.; ROCHA, M.G.; MACARI, S. et al. Desenvolvimento de bezerras de corte após a desmama sob níveis de concentrado. Cienc. Rural, v.40, p.2157-2162, 2010.

RESTLE, J.; SOARES, A.B.; FERREIRA, M.V.B. et al. Suplementação associada com lasalocida para novilhos em terminação em pastagem cultivada de inverno. Cienc. Rural, v.29, p.555-559, 1999.

ROCHA, M.G.; LOBATO, J.F.P. Sistemas de alimentação pós desmama de novilhas de corte para acasalamento com 14/15 meses de idade. Rev. Bras. Zootec., v.31, p.1814-1822, 2002.

SAS. Statistical Analysis System. SAS/STAT user guide, Version 9.2. Cary, NC: SAS Institute, 2009.

VAN SOEST, P.J. (Ed.). Nutritional ecology of the ruminant. Ithaca: Cornell University, 1994. $476 \mathrm{p}$.

VAN VUUREN, A.M.; VAN DER KOELEN, C.J.; VROONS-DE BRUIN, J. Ryegrass versus corn starch or beet pulp fiber diets effects on digestion and intestinal aminoacid in dairy cows. J. Dairy Sci., v.76, p.2692-2700. 